\title{
Orações adverbiais mirativas em português brasileiro
}

DOl: http://dx.doi.org/10.21165/el.v50i1.2918

\author{
Juliana Fernandes Corrêa Nunes ${ }^{1}$ \\ Patrícia de Araujo Rodrigues ${ }^{2}$
}

\section{Resumo}

O objetivo principal deste artigo é propor uma descrição inicial, com base nos estudos gerativistas, de um tipo de oração infinitiva do português brasileiro introduzida pelo conectivo para (Ana foi até o banco só para descobrir que esqueceu o cartão), que denominamos de oração mirativa (cf. JĘDRZEJOWSKI, 2018). Essas orações se assemelham às orações adverbiais finais infınitivas em sua forma, mas, diferentemente das finais, não expressam um sentido de finalidade, denotando sobretudo um desfecho contrário às expectativas. Mostramos que, além da diferença de sentido, as mirativas também se distinguem das finais no que se refere ao controle do sujeito do infinitivo e à sensibilidade a certas operações sintáticas, como deslocamento da oração. Mostramos ainda que, quando mirativas e finais coocorrem em uma sentença, a ordem entre elas deve ser finais-mirativas, o que indica que as mirativas estariam adjungidas a uma posição mais alta na estrutura.

Palavras-chave: subordinação; oração adverbial final; adjunção; oração mirativa.

\footnotetext{
1 Universidade Federal do Paraná (UFPR), Curitiba, Paraná, Brasil; julianacot@hotmail.com; https://orcid.org/0000-0002-8110-6979

2 Universidade Federal do Paraná (UFPR), Curitiba, Paraná, Brasil; patricia.rodrigues@ufpr.br; https://orcid.org/0000-0002-3534-284X
} 


\title{
Mirative adverbial clauses in Brazilian Portuguese
}

\begin{abstract}
The main goal of this paper is to propose an initial description, based on generative studies, of a type of infinitive clause in Brazilian Portuguese introduced by the connective para 'for' (Ana foi até o banco só para descobrir que esqueceu o cartão / Ana went to the bank only to find that she forgot her card), which we call mirative clause (cf. JĘDRZEJOWSKI, 2018). These clauses are similar to infinitive purpose clauses in their form, but they do not express a purpose, denoting mainly an unexpected result. We show that mirative clauses are also distinguished from purpose clauses regarding the control of the subject of the infinitive and the sensitivity to certain syntactic operations, such as displacement of the clause. We further show that the order between mirative and purpose clauses, when they co-occur in a sentence, must be purpose-mirative, which indicates that mirative clauses are adjoined to a higher position in the structure.
\end{abstract}

Keywords: subordination; purpose clauses; adjunction; mirative clauses.

\section{Introdução}

Neste artigo, examinamos as propriedades morfossintáticas e a interpretação de um tipo de oração infinitiva do português brasileiro introduzida pelo conectivo para, ilustrada em (1). Essas orações são superficialmente semelhantes às orações adverbiais finais infinitivas introduzidas por para (2), mas não possuem um sentido estrito de finalidade, expressando sobretudo surpresa, ou um desfecho inesperado. Assim, em (1), a finalidade de Ana ter ido ao banco não era, certamente, descobrir que havia esquecido o cartão em casa. Essa oração expressa um desfecho contrário às expectativas, diferentemente da oração infinitiva em (2), que expressa, de fato, a finalidade ou motivação da ida ao banco.

1. Ana foi até o banco só para descobrir que esqueceu o cartão em casa.

2. Ana foi até o banco para pegar um talão de cheques.

Esse tipo de oração está presente em outras línguas, como o inglês, o polonês e o alemão, e são denominadas na literatura de mirativas (cf. JĘDRZEJOWSKI, 2018)33 ou télicas (cf. WHELPTON, 1995). Seguindo Jędrzejowski (2018), adotaremos neste trabalho o termo mirativa para nos referirmos a essas orações. Consideramos que elas são orações adverbiais, tal como as orações finais, por funcionarem como um adjunto na oração. Com exceção de Nunes (2020), que aponta algumas das características das orações mirativas, elas não são discutidas nos trabalhos sobre o português.

3 Jędrzejowski (2018) adota o termo mirativas com base nos estudos de DeLancey (1997), que denomina dessa forma as categorias descritivas que denotam informação inesperada. 
O objetivo deste trabalho, que se insere no quadro geral dos estudos gerativistas, é propor uma descrição inicial para as orações mirativas em comparação com as orações finais. Tomaremos como base para essa descrição estudos sobre orações similares em inglês (FARACI, 1974; HUETTNER, 1989; JONES, 1991; WHELPTON, 1995, 2001), em alemão (JĘDRZEJOWSKI, 2018) e em polonês (JĘDRZEJOWSKI, 2019). Veremos que as orações mirativas, além de não apresentarem um sentido de finalidade, também se distinguem das orações finais infınitivas por denotarem um evento de fato ocorrido, por admitirem o controle do sujeito da infinitiva somente pelo sujeito da subordinante e por serem refratárias a algumas operações sintáticas possíveis com as orações finais. Além disso, a ordem entre as finais e as mirativas nas sentenças indica que as orações mirativas são adjungidas em uma posição mais alta na estrutura sintática do que as orações finais.

O artigo está organizado como segue. Na próxima seção, discutimos brevemente as orações infınitivas fınais, para fins de comparação com as orações mirativas. A terceira seção examina as propriedades das mirativas e discute as diferenças entre essas orações e as orações finais. Por fım, a quarta seção apresenta nossas considerações finais.

\section{Orações adverbiais finais infinitivas}

As tradicionalmente chamadas orações subordinadas adverbiais finais são geralmente caracterizadas como orações que expressam a finalidade, a intenção da ação expressa na oração matriz. Esta seção apresenta brevemente algumas das definições e propriedades dessas orações, discutidas tanto em estudos gramaticais tradicionais como em estudos linguísticos. Nos deteremos nas propriedades mais relevantes para a comparação com as orações mirativas. Uma descrição mais abrangente das orações finais infinitivas será deixada para estudos futuros.

Nas gramáticas tradicionais, a discussão sobre as orações subordinadas adverbiais finais não é aprofundada (BECHARA, 2019; CUNHA; CINTRA, 2001; ROCHA LIMA, 2010). A classificação dessas orações, com base em seu sentido, é, no entanto, geralmente mantida nos estudos linguísticos. Resumidamente, as gramáticas tradicionais tratam do significado dessas orações, dos conectivos que as introduzem (para (que), a fim de (que), entre outros ${ }^{4}$ ) e da sua classificação, como reduzidas, quando o verbo aparece no infinitivo (3a), ou como desenvolvidas, quando o verbo aparece no subjuntivo (3b).

3a. Ele ligou o computador para / a fim de verificar seu e-mail.

3b. Ele ligou o computador para / a fim de que pudesse verificar seu e-mail.

4 As gramáticas citam igualmente formas não usuais na introdução de orações finais, como porque e que. 
Nos estudos linguísticos, as descrições são mais aprofundadas. Neves (2011, p. 888), por exemplo, assume que a relação final, definida como "expressão da finalidade, ou do propósito que motiva o evento expresso na oração principal", é realizada mais frequentemente por uma oração no infinitivo, introduzida pela preposição para ou pela locução a fim de. A autora afirma que esses conectivos são, geralmente, aceitáveis no mesmo contexto (4) e que as orações finais infınitivas introduzidas por preposição não apresentam restrição quanto ao sujeito, havendo tanto orações com mesmo sujeito da matriz quanto orações com sujeito diferente ${ }^{5}$. Neves ressalta que o sujeito da oração infinitiva pode ser correferencial a qualquer outro membro da matriz (5). A autora afirma ainda que, tipicamente, a oração final está ligada a uma oração principal com sujeito agente, que pode exercer controle sobre o evento denotado na final (6); mas que, no caso de a oração principal indicar necessidade ou obrigação, esse controle agentivo pelo sujeito não seria necessário (7).

4. Já importou duzentos e cinquenta mil larvas de ostras para iniciar sua criação experimental. (AGF) (= a fim de iniciar) (NEVES, 2011, p. 885) ${ }^{6}$

5. Comprou oito hectares em arraial do cabo, para servir de base à criação de gigas. (AGF) (Ibid., p. 887)

6. Os rapazes faziam exercícios atléticos para mostrar agilidade e resistência. (AE) (Ibid., p. 888)

7. Cada período tem suas características precisas, e cada um deles [...] necessita ser compreendido e tratado com justeza e a tempo para não se constituir em fator irremediável de deformação. (AE) (Idem)

Neves não desenvolve a análise sobre a correferencialidade entre o sujeito da oração infınitiva e o sujeito da oração principal, nem sobre o tipo de controle do sujeito da infinitiva. No entanto, sua descrição aponta para uma distinção a ser feita entre as orações finais

5 Neves (2011) discute as finais infinitivas em comparação com as finais desenvolvidas, argumentando que essas orações apresentam comportamento distinto com relação à possibilidade de correferenciação do sujeito. De acordo com a autora, "as orações finais iniciadas por conjunção (em modo finito) constroem-se com sujeito diferente do da oração principal" (NEVES, 2011, p. 886). Não aprofundaremos a discussão sobre as finais desenvolvidas, pois o exame dessas orações foge ao escopo deste trabalho.

6 As abreviaturas que aparecem nos exemplos remetem aos textos examinados pela autora: AE Adolescência e sua educação. São Paulo: Ed. C. E. N. 1950. v. 52 / AGF - Agrofolha - Folha de São Paulo - Caderno agrícola - diversas edições. 
infinitivas circunstanciais ${ }^{7}$ : o sujeito da infinitiva pode ser controlado pelo sujeito ou por outro membro qualquer da oração principal. Veremos a seguir que essa distinção está descrita apenas parcialmente, pois há restrições com relação ao membro da oração principal que pode exercer controle sobre a oração final, além de não ser apenas o sujeito da final que pode ser controlado.

Nos trabalhos sobre orações similares do inglês, as propriedades de controle das orações finais são mais detalhadas (FARACI, 1974; HUETTNER, 1989; JONES, 1991; WHELPTON, 1995, 2001). Os autores mencionados reconhecem dois tipos de oração de finalidade, que eles denominam purpose clauses (cf. JONES, 1991) e rationale clauses (cf. FARACI, 1974) ${ }^{8}$. Conforme Whelpton (1995), as purpose clauses (8a) são sempre controladas pelo objeto ou tema do verbo matriz (a saga em (8a)); uma lacuna (gap) é obrigatória nessas orações (no caso de (8a), o elemento nulo complemento de read) ${ }^{9}$; e o infinitivo não pode ser precedido pela expressão in order (8b).

8a. Sven brought a saga along e to read e to his friends. (WHELPTON, 1995, p. 1)

Sven trouxe uma saga junto e para ler e para seus amigos

'Sven trouxe com ele uma saga para ler para seus amigos.'

8b. *Sven handed Ute the ice-cream in order e to put $e$ in the freezer. (Ibid., p. 5)

Sven entregou Ute o sorvete a fim de e para por e em o congelador

Com relação às rationale clauses (9), o autor afirma que elas não precisam conter um gap (9a), mas se um gap estiver presente (9b-c), ele deve estar na posição de sujeito e deve ser controlado por um agente (que não é necessariamente o sujeito da subordinante,

7 Neves (2011) distingue dois tipos de oração adverbial final infinitiva: as orações finais circunstanciais, que denotam a finalidade ligada ao evento da principal, e as orações finais de enunciação, que modificam o ato linguístico. Neste trabalho, examinamos apenas as infinitivas circunstanciais.

8 Os termos purpose "intenção" e rationale "justificação, razão" visam a exprimir as diferenças de sentido entre os dois tipos de oração. Neste artigo, não discutimos essas diferenças, nos restringindo a abordar as distinções sintáticas entres os dois tipos de oração. De modo geral, quando não for necessária a referência a um desses tipos particularmente, mantemos a denominação consagrada de orações finais para esse tipo de oração.

9 Nos exemplos do autor, e(mpty) representa o elemento nulo. 
podendo ser o agente da passiva (9c)) 10; além disso, essas orações podem ser precedidas pela expressão in order $(9 a / c)$.

9a. David spoke Welsh (in order) for Damian to feel more at home. (WHELPTON, 1995, p. 1)

David falou Welsh (a fim de) para Damian para sentir mais em casa

'David falou em galês a fim de / para Damian sentir-se em casa.'

9b. Sven worked at the newspaper e to earn money. (Idem)

Sven trabalhou em o jornal e para ganhar dinheiro

'Sven trabalhou no jornal para ganhar dinheiro.'

9c. The plutonium was stolen by the terrorists (in order) e to intimidate Western governments. (Idem)

O plutônio foi roubado por os terroristas (a fim de) e para intimidar ocidentais governos

'O plutônio foi roubado pelos terroristas a fim de / para intimidar governos do ocidente.'

Uma distinção dessa natureza é realizada em Duarte et al. (2011, 2015), em estudo sobre as relativas infinitivas finais do tipo de (10) em português europeu - nessa sentença, a oração introduzida por para modifica o nome faca. Para fins de comparação com as relativas infinitivas, as autoras se referem a dois tipos de adverbiais finais infinitivas: infinitiva final sem gap (11a) e infinitiva final com gap (11b), também possíveis em português brasileiro.

10. A faca para cortar pão está na gaveta.

11a. Comprei um portátil novo [para PRO agradar ao Pedro]. (DUARTE et al., 2015, p. 242)

11b. Trouxe [o artigo] $]_{i}$ para casa [para o Pedro rever $e_{i}$ logo]. (Ibid., p. 243)

10 Nos casos em que o agente da passiva não aparece explicitado na sentença, há autores que propõem que o antecedente do sujeito nulo de uma oração rationale seria um agente implícito, enquanto outros propõem que esse antecedente seria o próprio evento denotado pela oração subordinante. Vamos nos referir a esses casos como controle por um agente implícito. Remetemos o leitor a Landau (2017) para uma discussão sobre controle nas orações rationale. 
Duarte et al. $(2011,2015)$ denominam gap o elemento nulo obtido a partir de movimento. Assim, em (11a) $\mathrm{PRO}^{11}$ não é analisado como originado por movimento - a respeito desse exemplo, as autoras esclarecem que, devido à possibilidade de o português apresentar o infinitivo tanto flexionado como não flexionado, (11a) é na verdade ambígua entre uma oração infinitiva impessoal com sujeito PRO e uma oração infınitiva pessoal com sujeito pro. Já em (11b), o elemento nulo é analisado como uma variável, fruto do movimento de um operador. Essa é a análise adotada pelas autoras para as relativas infinitivas do tipo de (10) e estendida para as adverbiais finais infinitivas do tipo de (11b): uma análise com "o antecedente externo à oração relativa e uma cadeia operador-variável interna à referida oração"12 (DUARTE et al., 2011, p. 246). Comparando esses exemplos com os tipos de oração final do inglês, pode-se dizer que a oração em (11a) corresponderia ao tipo rationale, enquanto a oração em (11b) corresponderia ao tipo purpose.

Para discutir as sentenças do português brasileiro, adotamos a nomenclatura do inglês a fim de facilitar a comparação ${ }^{13}$. As sentenças em (12) seriam casos de orações purpose: há um elemento nulo em todas as orações e o seu antecedente é o objeto/tema do verbo matriz. Esse elemento nulo pode ser um sujeito (12a), um objeto (12b) ou um locativo (12c). Já em (13), as infinitivas corresponderiam às orações rationale: elas não precisam conter um elemento nulo (13a-b), mas se um elemento nulo estiver presente, ele ocupa a posição de sujeito e deve ser controlado por um agente (13b-c).

12a.. Maria ${ }_{1}$ levou o cachorro ${ }_{2}$ no petshop para _ ${ }_{2}$ tomar banho.

12b.. Maria deu o sorvete ${ }_{1}$ para o João pra ele colocar _

12c.. Maria abriu o congelador ${ }_{1}$ para o João colocar o sorvete __.

13a. Maria falou em português para o João poder participar da conversa.

13b. Maria ${ }_{1}$ comprou uma TV nova pra $\left\{\__{1} /\right.$ ela $\}$ poder acompanhar as olimpíadas.

13c. As ações foram vendidas para _ saldar as dívidas da empresa.

11 Na teoria gerativa, PRO e pro são tipos de sintagmas nominais nulos postulados como sujeitos de orações não finitas e finitas/infinitivas pessoais, respectivamente.

12 Na construção Comprámos uma manta para usar na praia, a oração introduzida por para pode ser uma oração relativa (i) ou uma oração adverbial (ii) (DUARTE et al., 2015, p. 256).

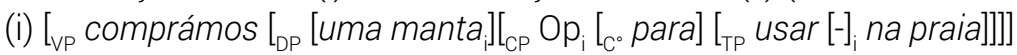

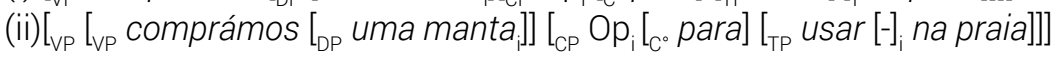

13 Vamos abstrair a questão do infinitivo ser flexionado/não flexionado e nos referirmos a um elemento nulo apenas; para essa descrição mais geral, não julgamos necessário determinar a natureza desse elemento. 
No inglês, as orações rationale, mas não as orações purpose, podem ser precedidas pela expressão in order. No português brasileiro, podemos utilizar o conectivo a fim de para verificar se há uma diferenciação a ser feita nesse sentido. Os exemplos em (14) mostram que as orações purpose do português brasileiro não aceitam o conectivo a fim de $e^{14}$. Já os exemplos em (15) mostram que a presença desse conectivo é aceitável nas orações rationale, mas não em todos os casos: a expressão a fim de só é aceitável quando a posição de sujeito da infinitiva não é preenchida. De todo modo, ainda que os usos da expressão a fim de não correspondam exatamente aos usos da expressão in order do inglês, essa expressão pode, aparentemente, ser usada para distinguir as orações finais infinitivas do português brasileiro com um elemento nulo na posição de sujeito ((14a) vs. (15a)).

14a. * Maria ${ }_{1}$ levou o cachorro 2 no petshop a fim de _ ${ }_{2}$ tomar banho.

14b. *Maria deu o sorvete ${ }_{1}$ pro João a fim de ele colocar _ _ no congelador.

14c. *Maria abriu o congelador ${ }_{1}$ a fim de João colocar o sorvete _ .

15a. Maria ${ }_{1}$ comprou uma TV nova a fim de $\left\{\ldots_{1} /{ }^{*}\right.$ ela $\}$ poder acompanhar as olimpíadas.

15b. *Maria falou em português a fim do João poder participar da conversa.

Vale notar ainda uma outra distinção entre orações rationale e orações purpose: elas podem coocorrer na sentença, mas na ordem purpose-rationale:

16a. Maria ${ }_{1}$ levou o cachorro ${ }_{2}$ no petshop [pra _ ${ }_{2}$ tomar banho] [pra _, agradar a mãe dela].

16b. * Maria ${ }_{1}$ levou o cachorro ${ }_{2}$ no petshop [pra _ ${ }_{1}$ agradar a mãe dela] [pra _ ${ }_{2}$ tomar banho].

Em síntese, essa discussão evidencia que é bastante plausível considerar a existência no português brasileiro dos dois tipos de oração adverbial final infınitiva já apontados para o inglês e para o português europeu. Como mencionado acima, não aprofundaremos

14 Os julgamentos de aceitabilidade para esses exemplos são nossos. Alguns falantes consultados julgam os exemplos estranhos, mas não são categóricos em não os aceitar. Uma busca no corpus NILC/São Carlos (https://www.linguateca.pt/acesso/corpus.php?corpus=SAOCARLOS) pela sequência "a fim de" + pronome pessoal + infinitivo não recuperou nenhum exemplo, o que corrobora, em certa medida, esses julgamentos. De qualquer forma, consideramos relevante para a discussão neste trabalho que (12) e (13) se distinguem de (14) e (15) com relação à aceitabilidade. 
a investigação sobre as propriedades das orações finais ${ }^{15}$. As propriedades discutidas até aqui - presença/ausência de um elemento nulo, posição e controle desse elemento, substituição de para por a fim de - servirão como parâmetros de comparação para a descrição das orações mirativas.

\section{Orações mirativas}

Como visto na introdução, as orações mirativas (1) têm a forma aparente de uma oração fınal, mas não apresentam o mesmo sentido de finalidade ou propósito, expressando sobretudo um fato inesperado como resultado.

Whelpton (1995) chama as orações desse tipo no inglês de télicas (17), porque, diferentemente das finais, elas denotam um evento que de fato ocorreu. Jędrzejowski $(2018,2019)$, que examinou esse tipo de oração no alemão (18a) e no polonês (18b), as denomina, como vimos, de mirativas, com base em seu sentido de "resultado surpreendente". Essas denominações refletem, assim, aspectos do sentido dessas orações. Como mencionado na introdução, a oração do português em (1) também possui o sentido relacionado à surpresa, além de denotar, da mesma forma, um evento efetivamente ocorrido. Observamos, assim, uma primeira distinção entre as mirativas e as finais.

17a. John entered the house, e to discover that everyone had already left. (WHELPTON, 1995, p. 6) John entrou a casa, e para descobrir que todos tinham já saído 'John chegou em casa, para descobrir que todo mundo já tinha saído.'

17b. John bought the house, only for his partner to discover that it had rising damp. (Idem) John comprou a casa, só para seu parceiro para descobrir que ela tinha ascendente umidade.

'John comprou a casa, só para seu/sua parceiro/a descobrir que ela tinha umidade (nas paredes).'

15 Há várias questões que devem ser estudadas no português brasileiro com relação às finais infinitivas. A discussão acima mostra, por exemplo, que, embora os conectivos para e a fim de sejam mencionados como introdutores de orações finais, há diferenças entre eles que ainda não foram devidamente investigadas. Além disso, há particularidades do português brasileiro que devem ser levadas em consideração em uma análise mais aprofundada das adverbiais finais infinitivas, por exemplo, o licenciamento de objetos nulos anafóricos e a existência do infinitivo pessoal. Ainda, a literatura sobre as orações do inglês aponta que há orações infinitivas que se assemelham às chamadas orações rationale, como John went out to smoke "João saiu para fumar", mas que teriam comportamento e significado diferente, que poderia ser evidenciado com a utilização de in order "a fim de" (cf. HUETTNER, 1989), e que as orações purpose teriam uma estrutura interna mais defectiva do que a estrutura das orações rationale (cf. JONES, 1991). 
18a. Alemão

Sie stellte den Regenschirm neben sich, um ihn dann doch zu vergessen

she put.3SG.PST the umbrella next REFL COMP him.ACC then DISC-PART to forget.INF

'She put the umbrella right next to herself only to forget it anyway.' (JĘDRZEJOWSKI, 2018, p. 2)

'Ela colocou o guarda-chuva bem perto dela só para esquecer.'

18b. Polonês

Anna uczyła się przez cały rok, żeby i tak nie zdać matury.

Anna learn.l-PTCP.3SG.F REFL through entire year COMP and SO NEG pass.INF school.leaving. exam

'Anna learned all the year only to not pass the school leaving exam anyway.' (JĘDRZEJOWSKI, 2019, p. 4)

'Anna estudou o ano todo só para não passar no exame final'.

Além disso, Whelpton (1995) afirma que, tal como as orações rationale, as orações télicas do inglês apresentam um elemento nulo opcional na posição de sujeito, mas que, diferentemente do que ocorre com aquelas orações, o elemento nulo deve ser controlado pelo sujeito da subordinante. Em outras palavras, o sujeito nulo de uma oração mirativa não pode ser controlado por um agente implícito.

No português brasileiro, como mostram os exemplos em (18) (=(1)) e em (19), é possível observar que as orações mirativas também apresentam um elemento nulo opcional na posição de sujeito e que, quando esse elemento nulo está presente, seu antecedente é o sujeito da oração principal: em (18), o antecedente é o DP Ana, e em (19b) e (19c), o antecedente é o sujeito nulo da principal.

18. Ana foi até o banco só para _ descobrir que esqueceu o cartão em casa.

19a. Ana deu banho no cachorro só pra ele rolar na terra dois minutos depois.

19b. Vieram na aula só para ficar conversando. (NUNES, 2020, p. 66)

19b. Comecei a assistir o filme para dormir na metade. (Ibid, p. 67)

Da mesma forma que no inglês, o antecedente de um elemento nulo não pode ser um agente implícito, como é o caso nas orações rationale. Os exemplos abaixo ilustram essa restrição: 
20a. João ${ }_{1}$ comprou uma geladeira nova só para _ do mês!

20b. \#Uma geladeira nova ${ }_{1}$ foi comprada só para _ do mês.

20c. Uma geladeira nova ${ }_{1}$ foi comprada só para _ ficar encostada sem uso na garagem.

21a. João 1 comprou uma geladeira nova para ${ }_{1}$ economizar na conta de luz.

21b. A geladeira nova foi comprada para _ economizar na conta de luz.

Na infinitiva rationale em (21a), o antecedente do elemento nulo é o sujeito da matriz, mas em (21b), o antecedente do elemento nulo na infinitiva não é o sujeito da matriz, o DP a geladeira, mas, sim, um agente implícito. No caso das mirativas, o contraste entre os exemplos em (20) mostra que o antecedente do elemento nulo deve ser o sujeito da matriz, nunca um agente implícito. Em (20a), o antecedente é o DP sujeito da matriz. Em (20b), a matriz está na forma passiva, logo um agente implícito está disponível para servir como antecedente do sujeito da infınitiva, mas, nesse caso, a leitura da oração como mirativa não está disponível, só a leitura de finalidade (pragmaticamente incongruente, no sentido de que ninguém compra uma geladeira nova com o propósito de ter sua conta de luz aumentada). Por outro lado, a leitura em que o antecedente do sujeito nulo da infinitiva é o sujeito da oração principal também não está disponível, dada a incompatibilidade semântica entre o elemento nulo, sujeito de pagar, e o antecedente, o DP a geladeira. Já a sentença em (20c), que também apresenta a matriz na passiva, permite a leitura mirativa porque o antecedente do elemento nulo é o sujeito da matriz e porque há compatibilidade semântica entre eles.

Vale observar igualmente que as orações mirativas não possuem uma configuração semelhante à das orações purpose, em que um elemento nulo na infinitiva tem como antecedente o objeto/tema da oração principal. Nesses casos, a leitura mirativa não é possível, como ilustrado pelos dados em (22).

22a. Ana levou o cachorro ${ }_{2}$ no petshop pra ${ }_{2}$ tomar banho.

22b. Ana ${ }_{1}$ levou o cachorro 2 no petshop só pra ele 2 morder o veterinário.

22c. Ana ${ }_{1}$ levou o cachorro ${ }_{2}$ no petshop só pra ${ }_{2}$ morder o veterinário. 
Para fins de comparação, (22a) é um exemplo de uma oração infinitiva do tipo purpose, visto que o elemento nulo na posição de sujeito dessa oração tem como antecedente o objeto/tema do verbo matriz, o cachorro. Em (22b), a oração infinitiva pode suscitar tanto uma leitura de finalidade quanto uma leitura mirativa. Na leitura de finalidade, Ana tinha uma determinada intenção ao levar o cachorro no petshop, e a infinitiva expressa essa intenção - a de que o cachorro mordesse o veterinário -, mas nada é possível concluir sobre o desfecho da ação. Na leitura mirativa, a infinitiva expressa tanto um desfecho inesperado, quanto um evento de fato ocorrido; ou seja, não era a intenção de Ana, ao levar o cachorro ao petshop, de que ele mordesse o veterinário, mas, inesperadamente, foi isso que aconteceu. Com essas duas leituras em mente, passemos à análise do exemplo em (22c), que apresenta uma única diferença com relação a (22b), um elemento nulo na posição de sujeito da infinitiva, no lugar do pronome ele. Nesse caso, a leitura mirativa, em quem o cachorro inesperadamente morde o veterinário, não é possível; apenas a leitura de finalidade está disponível: Ana levou o cachorro ao veterinário com o propósito de que ele mordesse o veterinário ${ }^{16}$. Em outras palavras, o elemento nulo sujeito de uma infinitiva mirativa não pode ter como antecedente o objeto/tema do verbo principal.

Além dessas propriedades, as orações mirativas, da mesma forma que as orações purpose, mas contrariamente às orações rationale, não são compatíveis com o conectivo a fim de, como mostram os exemplos em (23), que não aceitam a leitura mirativa. Observase também que, diferentemente de (23b), (23a) não permite uma leitura de finalidade, dada a factividade da construção ${ }^{17}$.

23a. Ana foi até o banco a fim de descobrir que esqueceu o cartão em casa!

23b. Comecei a assistir o filme a fim de dormir na metade!

Jędrzejowski $(2018,2019)$ examina outras propriedades sintáticas das mirativas e das finais em alemão e em polonês: escopo da negação, topicalização e interrogação parcial. O autor argumenta que as mirativas não recaem no escopo da negação, não podem ser topicalizadas, nem podem responder a uma pergunta, enquanto as orações finais apresentariam um comportamento oposto. Com base nesses testes, Jędrzejowski propõe que as mirativas seriam adjungidas a TP, enquanto as finais seriam adjungidas a VP. Nunes (2020) aplica esses testes às mirativas do português brasileiro e aponta para algumas nuances nos julgamentos.

16 Uma outra leitura de finalidade também é possível, ainda que pragmaticamente incoerente, se considerarmos que o antecedente do elemento nulo é o DP Ana.

17 Como observou um dos pareceristas anônimos deste artigo, a leitura de finalidade seria mais facilmente obtida na presença do complementizador se no lugar de que:

(i) Ana foi até o banco a fim de descobrir se esqueceu o cartão em casa. 
Apresentamos, a seguir, uma discussão sobre essas propriedades, acrescentando a operação de clivagem aos testes. As infinitivas finais (rationale) podem recair sob escopo da negação na matriz (24a), podem ser clivadas (24b), podem funcionar como resposta a uma pergunta (24c) e podem ser topicalizadas (24d). Lobo (2003) considera que essas propriedades indicam que a oração final do português está adjungida a uma posição baixa na estrutura da sentença, mais especificamente VP.

24a. Ana não foi ao banco para pegar um talão de cheques (foi ao banco para conversar com o gerente).

24b. Foi para conversar com o gerente que Ana foi ao banco na hora do almoço.

24c. Para que Ana foi ao banco? Para pegar um talão de cheques.

24d. Para conversar com o gerente, Ana foi ao banco na hora do almoço.

Quanto às orações mirativas, os julgamentos não são tão claros, conforme aponta Nunes (2020). Elas parecem poder recair sob o escopo da negação sem perder o sentido de surpresa, mantendo a denotação de um evento ocorrido. Por exemplo, a sentença (25a) poderia funcionar como uma réplica a alguém que já tivesse usado a construção mirativa Ele botou feijão no fogo pra queimar! Deve-se observar, no entanto, que, nesse caso, não há propriamente negação do evento denotado pela oração para queimar; a negação parece incidir especialmente sobre o grau alcançado pelo resultado da ação de se botar o feijão no fogo. Em outras palavras, não se nega que o feijão tenha queimado, nega-se que ele tenha queimado pouco, como se a avaliação considerasse uma escala de "queimação", com "queimar" em um ponto mais baixo da escala e "torrar" em um ponto mais alto. Assim, o resultado de se botar o feijão no fogo foi pior do que queimar, pois o feijão torrou, tendo sido, por isso, um resultado ainda mais surpreendente ${ }^{18}$. Dessa forma, em (25b), na qual os resultados da ação de colocar o feijão no fogo não aparecem em uma mesma escala, a negação é interpretada como negação do evento denotado pela oração para queimar e a leitura mirativa não é obtida.

25a. Ele não botou o feijão no fogo para queimar, botou para torrar! (NUNES, 2020, p. 75)

25b. Ele não botou o feijão no fogo para queimar, botou para descongelar.

18 Agradecemos a um dos pareceristas anônimos deste artigo por essa observação com relação à interpretação do dado em (25a). O exemplo em (25b) foi sugerido por ele. 
Nos casos de resposta a uma interrogativa parcial (26), a leitura mirativa também parece possível. A pergunta em (26) aparenta estar relacionada a uma finalidade, mas a resposta parece poder funcionar como uma oração mirativa, ou seja, ele queimou o feijão e isso não era esperado. No teste de clivagem (27), a oração infınitiva parece denotar o sentido de finalidade em (27a), mas com acento na infınitiva, como em (27b), ela não parece expressar uma finalidade, mas sim um resultado de fato ocorrido, além de inesperado.

26. Para que ele botou o feijão no fogo? Para queimar! (NUNES, 2020, p. 76)

27a. Foi para queimar que ele botou o feijão no fogo. (Ibid, p. 75)

27b. Foi (só) pra passar raiva que eu saí de casa hoje! (Idem)

Quando topicalizada, no entanto, a infinitiva parece perder a leitura mirativa, como observado por Jędrzejowski $(2018,2019)$ para o alemão e para o polonês. Assim, nas sentenças em (28), a infinitiva só possuiria a leitura de finalidade, pragmaticamente incongruente. No entanto, salientamos que uma leitura mirativa também parece possível, se a infinitiva recebe um acento mais marcado (foco) e a principal funciona como background.

28a. Para descobrir que tinha esquecido o cartão em casa, Ana foi ao banco.

28b. Para ele morder a funcionária, Ana levou o cachorro ao petshop.

28c. Pra passar raiva, saí de casa hoje.

Assim, as orações mirativas, em condições mais específicas, envolvendo fatores como a estrutura informacional, parecem apresentar um comportamento sintático similar ao das orações de finalidade com relação ao escopo da negação, à possibilidade de funcionar como resposta a uma interrogativa parcial à clivagem e mesmo à topicalização. Dado que os julgamentos relativos às mirativas não são muito claros, consideramos que não é possível afırmar, com base apenas na comparação entre essas propriedades sintáticas, que as orações mirativas se adjungem a TP, como proposto por Jędrzejowski. No entanto, uma propriedade que corroboraria a análise do autor, pelo menos com relação a haver uma distinção no nível de adjunção das mirativas e das finais, é a ordem estrita que se observa entre elas quando coocorrem na sentença: 
29a. Maria ${ }_{1}$ comprou um chocolate belga caríssimo [pra _ ${ }_{1}$ dar pro seu filho] (só) [pra _ 1 esquecer o pacote no taxi].

29b. * Maria ${ }_{1}$ comprou um chocolate belga caríssimo (só) [pra _ ${ }_{1}$ esquecer ele no taxi] [pra — dar pro seu filho].

Os exemplos em (29a-b) mostram que a ordem deve ser rationale - mirativa. Como vimos no final da segunda seção, as orações purpose e rationale também coocorrem em uma ordem estrita, purpose - rationale. O exemplo em (30) mostra que os três tipos de oração podem ocorrer na sentença na ordem purpose - rationale - mirativa. Essa restrição de ordem entre as orações infinitivas introduzidas por para aponta para diferentes posições de adjunção dessas orações.

30. Maria ${ }_{1}$ levou o cachorro ${ }_{2}$ no petshop [para _ [só pra ele se sujar todo no caminho de volta].

Em suma, as orações mirativas se distinguem das orações finais, de modo geral, por não expressarem finalidade e por denotarem um fato ocorrido. Mais especificamente, elas se distinguem das orações de tipo purpose por apresentarem um elemento nulo opcional e por este elemento nulo, quando presente, não poder ter como antecedente o objeto/ tema da oração principal. As mirativas também apresentam distinções com relação às orações de tipo rationale: não aceitam a substituição de para por a fim de e o antecedente do elemento nulo na posição de sujeito só pode ser o sujeito da principal, nunca um agente implícito. Com relação às operações sintáticas examinadas, consideramos que os julgamentos obtidos não permitem determinar o nível de adjunção das orações mirativas. Contudo, a observação da ordem estrita entre as mirativas e as finais em uma sentença indica que as mirativas seriam adjungidas a uma posição mais alta na estrutura que as orações finais.

\section{Considerações finais}

O principal objetivo deste artigo foi mostrar que o português brasileiro apresenta um tipo de oração infinitiva introduzida pelo conectivo para que se assemelha formalmente às chamadas orações adverbiais finais reduzidas de infınitivo, mas que não expressa finalidade. Essas orações, que denominamos mirativas, seguindo Jędrzejowski (2018), expressam um desfecho inesperado da situação denotada pela oração subordinante e um evento que de fato aconteceu.

Para fins de comparação, apresentamos, em primeiro lugar, várias propriedades das orações infinitivas finais. Vimos que é possível comparar essas orações às orações de finalidade do inglês, subdivididas, geralmente, em dois tipos: orações purpose e orações 
rationale, que se distinguem, principalmente, com relação à presença obrigatória/opcional de um elemento nulo na oração final e com relação ao antecedente desse elemento, quando ele está presente.

Em segundo lugar, partindo da descrição das orações finais, propusemos uma descrição para as orações mirativas, examinando primeiramente questões relativas à presença de um elemento nulo na infinitiva e ao controle desse elemento. Vimos que, da mesma forma que as orações rationale, as orações mirativas apresentam opcionalmente um elemento nulo na posição de sujeito, mas que esse elemento não pode ser controlado por um agente implícito, apenas pelo sujeito da subordinante. Assim, não é possível que o elemento nulo sujeito das mirativas seja controlado pelo objeto/tema da oração principal, o que também distingue as mirativas das orações purpose. Em seguida, analisamos a sensibilidade dessas orações com relação a algumas operações sintáticas envolvendo a focalização da oração. No caso das orações finais, os resultados dessas operações são tidos como aceitáveis, o que levou autores como Lobo (2003), por exemplo, a proporem que essas orações são adjungidas a VP. Já, com relação às orações mirativas, dada a falta de clareza nos julgamentos de aceitabilidade, não consideramos possível determinar que essas orações são adjungidas a TP, como propôs Jędrzejowski. Contudo, a ordem obrigatória finais-mirativas observada aponta para a adjunção das mirativas a uma posição mais alta na estrutura. Estudos futuros mais aprofundados sobre as condições específicas subjacentes à dificuldade na avaliação dos resultados das operações sintáticas examinadas são necessários para entendermos melhor o papel das propriedades observadas na definição da sintaxe tanto externa quanto interna das orações mirativas.

Por fim, ainda que a descrição proposta neste artigo não tenha se aprofundado na definição da sintaxe das orações mirativas, acreditamos que ele tem o mérito de contribuir com uma descrição inicial de um tipo de oração até então não abordada no português brasileiro, além de apontar para aspectos das orações finais ainda não discutidos na literatura.

\section{REFERÊNCIAS}

BECHARA, E. Moderna gramática portuguesa. 39. ed. Rio de Janeiro: Nova Fronteira, 2019.

CUNHA, C.; CINTRA, L. Nova Gramática do Português Contemporâneo. 3. ed. Rio de Janeiro: Nova Fronteira, 2001.

DELANCEY, S. Mirativity: the grammatical marking of unexpected information. Linguistic Typology, [S. I.], v. 1, p. 33-52, 1997.

DUARTE, I.; SANTOS, A. L.; ALEXANDRE, N. How relative are purpose relative clauses? Probus, [S. I.], v. 27, n. 2, p. 237-269, 2015. 
DUARTE, I.; SANTOS, A. L.; ALEXANDRE, N. Quão relativas são as relativas finais? In: COSTA, A.; BARBOSA, P.; FALÉ, I. (org.). Textos Seleccionados do XXVI Encontro da Associação Portuguesa de Linguística. Lisboa: APL, 2011. p. 242-255.

FARACI, R. A. Aspects of the grammar of infinitives and for-phrases. 1974. Tese (Doutorado em Linguística e Literatura) - Massachusetts Institute of Technology, Cambridge, 1974.

HUETTNER, A. Adjunct Infinitives in English. 1989. Tese (Doutorado em Linguística) University of Massachusetts, Amherst, 1989.

JĘDRZEJOWSKI, Ł. On Adverbial Mirative Clauses in Polish. [S. I.], 2019. Disponível em: http://rgdoi.net/10.13140/RG.2.2.16913.68967. Acesso em: 23 abr. 2020.

JĘDRZEJOWSKI, Ł. Sentential adjuncts in flux. Evidence from the diachrony of German um-zu-clauses. In: III GETEGRA INTERNATIONAL WORKSHOP ADJUNCTS, 2018. Universidade Federal Rural de Pernambuco: [s. n.], 2018.

JONES, C. Purpose Clauses. Berlin: Springer Science+Business Media, 1991.

LANDAU, I. Adjunct control depends on voice. In: HALPERT, C.; KOTEK, H.; VAN HURK, C. (org.). A Pesky Set: Papers for David Pesetsky. Cambridge, MA: MIT Working Papers in Linguistics, 2017. Disponível em: lingbuzz/003322. Acesso em: 23 abr. 2020.

LOBO, M. Aspectos da sintaxe das orações subordinadas adverbiais do português. 2003. Tese (Doutorado em Linguística) - Universidade Nova de Lisboa, Lisboa, 2003.

NEVES, M. H. de M. Gramática de usos do português. 2. ed. São Paulo: Editora UNESP, 2011.

NUNES, J. F. C. Orações subordinadas adverbiais finais: aspectos sintáticos. 2020. Dissertação (Mestrado em Letras) - Universidade Federal do Paraná, Curitiba, 2020.

ROCHA LIMA, C. H. Gramática normativa da língua portuguesa. Edição revista segundo o novo acordo ortográfico. Rio de Janeiro: José Olympio, 2010.

WHELPTON, M. Elucidation of a telic infinitive. Journal of Linguistics, [S. I.], v. 37, n. 2, p. 313-337, jul. 2001.

WHELPTON, M. The syntax and semantics of infinitives of result in English. 1995. Tese (Doutorado em Linguística) - University of Oxford, Oxford (UK), 1995. 